\title{
A INTOLERÂNCIA LINGÜÍSTICA NA IMPRENSA
}

\author{
Marli Quadros Leite*
}

\begin{abstract}
Resumo: Este trabalho inscreve-se no âmbito das pesquisas do LEI Laboratório de Estudos da Intolerância - especificamente, no grupo de pesquisas de Lingüística, que tem como principal objetivo "examinar a intolerância e o preconceito lingüísticos no Brasil $e$ as formas de resistência desencadeadas, tanto em relação às variantes de uma mesma lingua, quanto em relação a outras línguas". Pretende-se aqui estabelecer uma diferença entre preconceito e intolerância lingüísticos, com base nos textos de Voltaire (1764) e Bobbio (1990), para analisar um caso de intolerância lingüística veiculado pela imprensa escrita. Examinarei, então, um artigo da articulista do jornal "O Estado de São Paulo", Dora Krammer, publicado em 26/01/2005, cujo título é Em nome da lei do pior esforço, pelo qual a articulista manifestou opinião, repercutida em nível nacional, e, assim, comentar por que discursos como esses podem ser interpretados como intolerantes.
\end{abstract}

Palavras-chave: intolerância lingüística; preconceito lingüístico; discurso; língua portuguesa.

\section{Preliminares}

O Laboratório de Estudos da Intolerância - LEI - acolhe dentre os seus grupos de pesquisa um de Linguística. Como a intolerância lingüística passa quase despercebida pela opinião pública e não provoca sérios abalos sociais, da mesma forma que os provenientes da intolerância religiosa ou política, parece nem existir. Contudo, a intolerância lingüística existe e é tão agressiva quanto outra qualquer, pois atinge o cerne das individualidades. A linguagem, conforme disse Halliday (1974), é o que o homem tem de mais íntimo e representa a sua subjetividade. Portanto, não é exagero dizer que uma crítica lingüística é uma arma que fere como todas as armas.

O objetivo do grupo da Lingüística no LEI é, conforme está registrado no Projeto, "examinar a intolerância e o preconceito lingüísticos no Brasil e as formas de resistência desencadeadas, tanto em relação às variantes de uma mesma língua, quanto em relação a outras línguas". Os pesquisadores envolvidos nesse trabalho são:

Diana Luz Pessoa de Barros - Coordenadora, que examina os discursos de aceitação e de rejeição dos usos de termos estrangeiros no português do Brasil;

Margarida Maria Tadoni Petter, que, pelos jornais ilustrados do século XIX, estuda a intolerância lingüística contra o negro e formas de resistência à sua fala.

Ronald Beline Mendes (DL-FFLCH), que analisa, dentro do projeto variação lingüística e intolerância, o falar do homossexual masculino na cidade de São Paulo.

Marli Quadros Leite, que pesquisa a natureza da intolerância lingüística veiculada pela mídia impressa.

Como o título de nosso projeto é "Intolerância e preconceito lingüísticos", com o adjetivo no plural, fica evidente a opção pela distinção dos dois fenômenos. Para esclarecer isso, então, procurarei mostrar como se pode chegar a essa diferença.

\footnotetext{
* Professora do Departamento de Letras Clássicas e Vernáculas - FFLCH-USP.
} 


\section{Relação preconceito e intolerância}

Pode-se dizer, mesmo, que falar em intolerância lingüística é uma tarefa diferente, já que o usual é, apenas, a referência ao preconceito. Por isso, cabe aqui refletir, antes de tudo sobre a relação, de semelhança ou divergência, que estes dois termos guardam entre si. A fim de levantar o problema da possível distinção que se pode fazer quanto aos sentidos das palavras preconceito e intolerância, examinarei, primeiro, suas acepções frias, em "estado de dicionário", para verificar que sentidos já ficaram registrados nos dois casos. Depois, comentarei como já se tratou desse tema no âmbito da filosofia, lembrando o que disse Voltaire, em 1764, e Norberto Bobbio, em 1990.

Nos mais recentes dicionários do português, vê-se que as palavras estão equiparadas numa relação de sinonímia. Diz, por exemplo, Houaiss que o preconceito é:

1. qualquer opinião ou sentimento, quer favorável quer desfavorável, concebido sem exame crítico;

1.1 idéia, opinião ou sentimento desfavorável formado a priori, sem maior conhecimento, ponderação ou razão.

2. atitude, sentimento ou parecer insensato, esp. de natureza hostil, assumido em consequiência da generalização apressada de uma experiência pessoal ou imposta pelo meio; intolerância.

3. conjunto de tais atitudes.

4. Rubrica: psicanálise. qualquer atitude étnica que preencha uma função irracional específica, para seu portador.

E, ainda, apresenta a locução preconceito lingüístico:

p. lingüístico Rubrica: lingüística. qualquer crença sem fundamento científico acerca das línguas e de seus usuários, como, p.ex., a crença de que existem línguas desenvolvidas e línguas primitivas, ou de que só a língua das classes cultas possui gramática, ou de que os povos indígenas da África e da América não possuem línguas, apenas dialetos.

Quanto à intolerância, vê-se no mesmo dicionário:

1. falto de tolerância, de condescendência, de compreensão; inflexível, rígido.

2. que não admite opinião, posição etc. que divirja da sua.

Como se observa, o sentido do termo se faz por oposição a tolerância, e essa remissão obriga a sua consulta:

1. que tolera.

2. que desculpa certas falhas ou erros.

3. diz-se de ou indivíduo que é dotado de tolerância ou indulgência.

À primeira vista, pode-se dizer, simplesmente, que as palavras são sinônimas. Um exame um pouco mais detido, contudo, pode mostrar que preconceito é a idéia, a opinião ou sentimento que pode conduzir o indivíduo à intolerância, à atitude de não admitir opinião divergente da sua. Isso indica uma primeira diferença: o traço semântico mais forte registrado no sentido de intolerância é ser um comportamento, uma reação a uma idéia ou opinião contra a qual se podem apor objeções e, portanto, não se constitui, 
simplesmente, como uma discordância tácita. Um preconceito, ao contrário, pode jamais se revelar e, por isso, existe antes da crítica.

Voltaire, no Dicionário Filosófico ${ }^{1}$, delineia certa diferença entre os termos, pois ao definir preconceito diz "o preconceito é uma opinião sem julgamento" e, ainda mais, até afirma a existência de "preconceitos universais, necessários que representam a própria virtude", dentre os quais cita a crença em "um Deus remunerador e vingador" (p. 428). Do que se conclui que admitia o bom e o mau preconceito. No Dicionário Filosófico não há o verbete intolerância, mas se pode chegar a seu conceito pelo de tolerância, definida como o "apanágio da humanidade", isto é, um privilégio, uma regalia, uma vantagem, característica que, como se sabe, não é inerente a todos os seres humanos, em todas as circunstâncias de suas vidas. A ausência da tolerância, conforme se pode deduzir do discurso de Voltaire, é a dificuldade de o ser humano aceitar bipolaridades, especificamente as religiosas, e pode levar o homem a um comportamento agressivo (Voltaire não usa o termo intolerância), à perseguição do adversário. São essas as suas palavras quando se refere ao homem a quem falta a tolerância: "É claro que todo indivíduo que persegue um homem, seu irmão, porque não é da mesma opinião, é um monstro.".

Para não ficar restrita a um conceito de século XVIII, tomem-se as idéias do filósofo italiano, nosso contemporâneo, Norberto Bobbio (1992: 203-04). Ao tratar das razões da tolerância, esse filósofo examina dois dos principais significados que a palavra tolerância tem e, a partir disso, formula os conceitos de preconceito e intolerância. O termo tolerância, diz ele, pode, em seu sentido mais comum, ser empregado em referência à aceitação da diversidade de crenças e opiniões, principalmente religiosas e políticas. A intolerância, conclui-se do que diz o autor, refere-se à incapacidade de o indivíduo conviver com a diversidade de conceitos, crenças e opiniões e, o que é essencial, gera discursos sobre "a verdade" (ou verdades) e, também, sobre a compatibilidade/incompatibilidade teórica ou prática entre duas verdades que se contrapõem. Afirma o autor, textualmente, que

hoje, o conceito de tolerância é generalizado para o problema da convivência das minorias étnicas, lingüísticas, raciais, para os que são chamados geralmente de 'diferentes', como, por exemplo, os homossexuais, os loucos ou os deficientes.

Já o preconceito, segundo a concepção do citado filósofo, embora tenha em comum com o significado de intolerância a não aceitação da diferença do outro, não leva o sujeito à construção de um discurso acusatório sobre a diferença, porque o preconceito pode construir-se sobre o que nem foi pensado, mas somente assimilado culturalmente, sobre irracionalidades ou sobre emoções e sentimentos. O preconceito pode redundar em uma discriminação, mas não se manifesta discursivamente sobre argumentos que visam a sustentar "verdades".

Apesar de as duas concepções examinadas serem diferentes, pode-se extrair de ambas a mesma lição: o preconceito não surge, exclusivamente, de uma dicotomia, pode ser uma rejeição, um "não-querer" ou um "não-gostar" sem razão, amorfo e, até, pode não se manifestar; a intolerância nasce, necessariamente, de julgamentos contrários e se manifesta discursivamente. É resultado da crítica e do julgamento de idéias, valores e opiniões.

A partir do campo dessa temática filosófica, especificamente em relação à língua, pode-se falar tanto de preconceito quanto de intolerância, reconhecendo,

\footnotetext{
${ }^{1}$ Citado pela edição da Martin Claret, 2004.
} 
contudo, diferenças entre ambos. O preconceito é a discriminação silenciosa e sorrateira que o indivíduo pode ter em relação à linguagem do outro, é um não-gostar, um achar feio ou errado um uso (ou uma língua), sem que se tenha a configuração do que poderia vir a ser o bonito ou correto. A intolerância, ao contrário, é ruidosa, explícita, porque, necessariamente, se manifesta por um discurso metalingüístico, calcado em dicotomias, em contrários, como, por exemplo, tradição $x$ modernidade, conhecimento $x$ ignorância, saber x não-saber, e outras congêneres.

\section{A intolerância lingüística na imprensa}

Diante do exposto, pode-se justificar a atuação dos lingüistas no âmbito do combate à intolerância, para analisar casos de intolerância lingüística. Neste artigo, o objeto é um artigo veiculado pela imprensa. Como o tema é amplo, escolhi comentar discursos recentes, publicados neste ano, e em que a dicotomia que os sustenta seja conhecimento x ignorância. Por acaso, ou não tão por acaso assim, o objeto desses discursos é o português, segundo essas vozes, "mal falado" do presidente da república, que o incapacita para o desempenho de sua tarefa.

Esse problema que parece fácil de ser resolvido é, em verdade, um enigma. Meu objetivo não é defender posições, nem resolver a questão da norma lingüística praticada no Brasil, mas, simplesmente, analisar discursos metalingüísticos, manifestados em textos jornalísticos de diferentes gêneros, para mostrar como e por que podem ser considerados intolerantes. Aqui, examinarei um artigo da articulista do jornal "O Estado de São Paulo", de Dora Krammer, publicado em 26/01/2005, cujo título é Em nome da lei do pior esforço, pelo qual a articulista manifestou opinião, repercutida em nível nacional. O objetivo é, então, comentar por que discursos como esses podem ser interpretados como intolerantes.

Como vou analisar aqui um artigo que tem como tema o discurso e a língua do Presidente Luís Inácio Lula da Silva, vale a pena lembrar (embora saiba que o público leitor desta revista está habituado ao trabalho científico) que o meu objeto de estudo não é o discurso do presidente, mas o discurso metalingüístico de quem o analisou. Minha postura, portanto, diante disso é eminentemente científica (e não político-partidária), com o objetivo de analisar a metalinguagem para mostrar como se constituem, pela declaração da não aceitação do discurso do outro, fatos de intolerância lingüística. Isso significa que não venho defender nem acusar as partes envolvidas no problema: nem o interpretado, o presidente, nem os interpretantes, os articulistas.

Antes de partir para a análise, penso ser proveitoso tecer breves comentários sobre a natureza do problema lingüístico brasileiro que leva as pessoas, em geral, a serem partidárias e apaixonadas nas defesas de opiniões favoráveis à liberdade total da língua em relação às regras da tradição. Há fatos incontestáveis sobre a prática das línguas em todos os tempos e um deles é a existência, para as línguas não ágrafas, de:

$1^{\text {o }}$ uma força diversificadora, que impulsiona a variação regional, social, estilística e temporal (sobrepostas em todas as emissões lingüísticas), inerentes à língua;

$2^{\circ}$ uma força unificadora, representada pelo império da tradição de um conjunto de usos lingüísticos, historicamente considerados como próprios dos que mais estudaram e acumularam conhecimentos por meio de leituras. Essa é culturalmente construída, portanto, secundária em relação à anterior. 
A dialética dessas duas forças cria condições de estabilidade da língua, isto é, permite que os falantes de certa geração tenham a ilusão de que a língua praticada é estável, embora sejam naturais, a todas as línguas, os fenômenos da variação e da mudança, do mesmo modo e no mesmo passo como varia e muda a vida do homem na sociedade. Ocorre, todavia, que a segunda força, a unificadora, ao contrário da primeira, mais deletéria, materializa-se na forma, de um lado, de instruções e regras - que formam os manuais de gramática tradicional e outros congêneres - e, de outro, de listas de palavras já atualizadas, acompanhadas da apresentação de seus respectivos significados, ou acepções - que formam os dicionários. Além disso, a gramática e os dicionários são instrumentos lingüísticos divulgados na escola. Disse Aléong (1983) que esses instrumentos (gramática e dicionário) e mais a escola formam um "aparelho de referência" dessa tradição lingüística.

Disso se pode facilmente concluir que, nos países em que todos (ou a maioria, pelo menos) os habitantes passam pela escola, a tradição da língua praticada é mais conhecida e fica, assim, à disposição dos falantes. Esses podem, em cada situação discursiva, optar tanto por uma emissão mais próxima quanto por uma mais distante dessa tradição. A realidade brasileira não é essa, mas a de a maioria não ter acesso à escola. E o problema não é só esse, porque a minoria escolarizada está dividida entre os que tiveram acesso a uma boa (ou regular) escola e os que tiveram uma escola ruim, que nem mesmo soube manejar esse aparelho de referência da tradição. Conclui-se que essa tradição esteja menos disponível a mais falantes brasileiros e daí vem o preconceito (aqui é preconceito mesmo) de que o brasileiro não sabe "falar português".

Particularizando a situação, agora, temos o seguinte quadro:

- De um lado, os interpretantes da prática lingüístico-discursiva de um brasileiro, ambos conhecedores da tradição da língua. Para empregar termos lingüísticos, ambos praticantes, também, da norma culta ou da norma padrão.

- De outro lado, o interpretado, o discurso (e por que não dizer a pessoa?) de alguém que não conhece bem a tradição da língua. (Os motivos por que não conhece não interessam nesse caso por já extrapolarem o âmbito do lingüístico.)

Esses são os fatos. Passemos, a seguir, ao discurso sobre eles, tomando o discurso de Dora Krammer, no texto Em nome da lei do pior esforço. A tese da autora, baseada na bipolaridade, nos contrários, saber x não-saber [a tradição], ou no conhecimento x ignorância [da tradição] ${ }^{2}$, é a de que o presidente deixa de fazer, intencionalmente, uso da variante culta da língua com objetivos políticos, pois, assim, poderia angariar, ou resgatar, a simpatia dos milhões de eleitores não praticantes dessa variante. Seria, pois, uma intenção política.

A autora, porém, vai muito além da desqualificação da fala do presidente, ela faz uma desqualificação do dialeto do brasileiro que fala como o presidente, embora o foco no texto seja o inverso, pois é o presidente que fala como o povo, e isso é o que, realmente, é importante. O problema da crítica ao presidente fica atenuado porque, se a variante empregada por Lula em algumas situações é intencional, fica pressuposto que ele sabe, e pode, usar outra variante, a de prestígio. Mas o discurso de Krammer é

\footnotetext{
${ }^{2} \mathrm{Cf} .4^{\circ} \S$ no texto anexo.
} 
contraditório neste ponto, porque o discurso denuncia um descompasso argumentativo, já que a uma declaração é ao mesmo tempo afirmada e negada. Observemos a frase ${ }^{3}$

Considerando que o presidente sabe falar normalmente (sem preciosismos, mas no limite do linguajar aceitável) quando quer (....)

que traz a declaração de que a fala do presidente é normal, isto é, mais próxima da tradição: há aí uma frase parentética que restringe a afirmação duas vezes, por meio de duas estratégias diferentes, primeiro por meio de uma atenuante da declaração precedente, a locução prepositiva "sem preciosismos"; depois há a restrição pela adversativa mas que introduz o argumento de que o "falar normalmente" fica no limite do aceitável. A negação definitiva da normalidade da fala do presidente aparece dois parágrafos depois, na seguinte afirmação ${ }^{4}$ :

Se os não-instruídos falam errado o português, certamente a maioria não o faz por escolha, charme ou diversão, mas por obra das deformações sociais por todos amplamente conhecida e pelo presidente sistematicamente lembrada (....) (Grifei)

Se ele fala "sistematicamente" errado, como disse, fica negada a tese da ocasionalidade e da escolha. O que indica que a afirmação anterior foi formulada apenas por um recurso de polidez, para que a autora salvaguardasse sua imagem positiva.

O texto, contudo, é construído sobre o argumento da intencionalidade do emprego da variante popular pelo presidente, o que se vê desde a colocação do problema, no primeiro parágrafo:

Há de haver uma explicação para o empenho do governo em geral e do presidente Luiz Inácio Lula da Silva em particular na consolidação do pensamento banal, da palavra tosca e do ato irrelevante como valores representativos do caráter nacional.

A reposta a essa pergunta implícita é, conforme registra Krammer, o populismo com vistas à reeleição, como já comentado. $\mathrm{O}$ trecho citado é importante porque revela a ideologia de que a língua condiciona o pensamento e, conseqüentemente a ação; logo, que um falante de uma variante que não seja a culta nem pensa nem age de modo inteligente. E aí reside o problema.

A lei do pior esforço é referente, exatamente, ao esforço de Lula falar como o brasileiro, como a maioria, o povão. O adjetivo do título do texto nos obriga a observar a seleção lexical da autora já que o pior é falar como o povo cujo dialeto, por comparação implícita ao do presidente, é (des)qualificado por meio de expressões negativas como: (nivelamento por) baixo, deficiente, insuficiente, despreparado, deformado, extravagante. Em suma, é anormal e deve ser combatido 5 :

Trata-se, portanto, não de uma situação a ser enaltecida mas de algo a ser combatido (...).

\footnotetext{
${ }^{3}$ Cf. $12^{\circ} \S$ no texto anexo.

${ }^{4} \mathrm{Cf} .14^{\circ} \S$ do texto anexo.

${ }^{5} \mathrm{Cf} .15^{\circ} \S$ do texto anexo.
} 
Já que a premissa é a do condicionamento língua/pensamento/ato, a autora entende que os erros de língua levam a erros de discurso, quando diz ${ }^{6}$ :

A conjunção de argumentos irrelevantes -'duvido que haja no mundo um país que tenha uma correio como o nosso' -, raciocínios triviais -'Deus não elege um pernambucano de Caetés todo ano' -, com um português ofensivo à nacionalidade - 'a gente quer ser gentis" - e conceitos socialmente excludentes - 'para os de cima o pobre tem que ser pobre a vida inteira' - não combina com os atributos até congênitos de alguém que foi capaz de chegar à Presidência da República.

O dialeto do presidente é caracterizado pela palavra "companheirês", escrita entre aspas, que indicam que a referência não se limita ao neologismo, servem também para ironizar a escolha da variante linguiística popular. O "companheirês", como foi denominado, o dialeto dos milhões que elegeram o presidente, e não propriamente o dialeto de Lula, é conceituado como uma desqualificação do idioma ${ }^{7}$ :

Não faz jus à campanha do governo de incentivo auto-estima do brasileiro a suposição de que para agradar aos humildes seja necessário dirigir-se a eles num 'companheirês' que desqualifica o idioma.(Grifei)

A idéia da equiparação do dialeto de Lula ao do povo é ainda mais clara quando a autora conjetura se, realmente, a opção pelo emprego do dialeto popular seria uma estratégia de propaganda e marketing em prol da reeleição do presidente. Nesse momento, a autora aproxima explicitamente o dialeto do presidente ao dialeto do povo brasileiro, pelo menos ao daqueles milhões que votaram em Lula, disse ela ${ }^{8}$ :

Será cruel com o Brasil se o departamento de marketing do Palácio do Planalto estiver, como parece, empenhado em sustentar a campanha para a reeleição no enaltecimento da figura do presidente da República como o "brasileiro igualzinho a você", ressuscitando um já tentado e malsucedido, lema de jornada eleito anterior.(Grifei)

$\mathrm{Na}$ opinião da autora, Lula ganhou a eleição de 2002 porque abandou essas características populistas e procurou assemelhar-se ao padrão de classe média, tanto em relação à indumentária quanto à linguagem. E a expressão que escolheu para caracterizar a situação anterior, ou seja, a proximidade dialetal presidente/povo, foi "nivelamento por baixo", já para a mudança de situação e padrão, ou seja aproximação presidente/classe média, escolheu a expressão metafórica "vestiu um figurino", numa remissão aos ternos Armani que o presidente, supostamente, passou a usar na ocasião da campanha, fato exaustivamente comentado na imprensa. Disse a articulista ${ }^{9}$ :

Em 2002, Lula abandonou o nivelamento por baixo, vestiu um figurino mais próximo da representação da média da sociedade e ganhou a eleição.(Grifei)

O padrão de linguagem da classe média brasileira, em geral, não é o mais próximo da tradição, também o padrão de figurino não é Armani... a exigência está bem acima da realidade.

\footnotetext{
Cf. $15^{\circ} \S$ do texto anexo.

${ }^{7} \mathrm{Cf} .13^{\circ} \S$ do texto anexo.

${ }^{8}$ Cf. $16^{\circ} \S$ do texto anexo.

${ }^{9} \mathrm{Cf} .17^{\circ} \S$ do texto anexo.
} 
O foco da análise, explícita, de Dora Krammer é a linguagem de Lula, mas não escapou da avaliação do governo depois dessa observação da "melhora de padrão". Segundo suas palavras, o governo vai bem, porque o mais importante, a economia, está correspondendo às expectativas dessa classe média referida (a que veste Armani). A conclusão do parágrafo anteriormente citado é :

De certa forma e no crucial - a economia - ficou dentro do parâmetro e surpreendeu favoravelmente. (Grifei)

Se tudo, então, está bem, pode-se perguntar, por que o temor aparente detrás da crítica ao discurso/língua do presidente? É que, declara a autora, a economia vai bem, mas a maior parcela da sociedade vai mal porque, ao atender um setor social, o presidente deixou de atender ao outro. E se, na primeira mudança atendeu à classe média, na segunda (na "regressão ao ponto de origem", como disse, pode querer agradar à parcela esquecida e, quem sabe, descuidar da economia. A organização linguiística desse argumento, posto em um período encabeçado por uma oração que traz a afirmação do déficit social do governo - "A escolha [pela economia] rendeu perdas na base social de origem [a maioria que não integra o padrão da classe média]" conectada à outra, pela conjunção adversativa "mas", para aduzir o segundo argumento, em que traz avaliação da situação atual do País - "MAS manteve o País à tona."-, posiciona toda a força argumentativa na segunda, e leva o leitor à seguinte inferência: "não importa se o povo está mal, importa que a economia esteja bem". Fica, assim, claro, que o importante é a manutenção do padrão da classe média, em todos os sentidos, inclusive o lingüístico, embora pareça que o texto traga reclamação maior sobre a linguagem.

O parágrafo conclusivo do texto traz o mesmo raciocínio. Primeiro, a aceitação da situação resumida numa oração absoluta "É um caminho.", depois sua rejeição categórica numa estrutura lingüística concessiva: "Legítimo e admissível, DESDE QUE não signifique a imposição do império da lei do pior esforço a um país tão carente de qualificação.”. Fica a pergunta: o que seria o caminho legítimo e admissível?

\section{Conclusão}

A intolerância do texto fica por conta da rejeição, denunciada pelo discurso da autora, aos que ignoram a tradição da língua e, que, portanto, são incompetentes para o desempenho de atividades que exijam algum esforço intelectual. Essa conclusão foi concretizada no texto de outro articulista, Gilberto de Mello Kujawski, que, no dia 17 de fevereiro, em sua coluna, no mesmo jornal, incorporou o discurso de sua colega e arrematou, confirmando a argumentação aqui desenvolvida:

O falar errado de Lula não constitui um dado isolado e sem consequiências. Sua "palavra tosca" arrasta consigo o 'pensamento banal', que, por sua vez, responde pelo "ato irrelevante".

Para concluir, lembro que essa foi a frase citada na revista VEJA, edição 1893, da semana de 23 de fevereiro, na coluna de frases da semana VEJA ESSA. Engraçado...

Restam dúvidas sobre o caráter intolerante do discurso examinado? 


\section{Referências bibliográficas}

ALÉONG, Stanley (1983). Normes linguistiques, normes sociales, une perspective antropologique. In: Édith Bedart \& Jacques Maurais. La norme linguistique. Paris : LeRobert.

BOBBIIO, Norberto (1992). A era dos direitos. Trad. Carlos Nelson Coutinho. Rio de Janeiro. [1990]

HALLIDAY, M. K. et. al. (1974). Os usuários e os usos da língua. In: As ciências lingüísticas e o ensino de línguas. Trad. Myriam F. Morau. Petrópolis : Vozes. MARCUSE, Herbert . Tolerância repressiva. In: MARCUSE, Herbert; WOLFF, Paul; MOORE, Barrington(1969) . Crítica da tolerância pura. Rio de Janeiro : Zahar.

VOLTAIRE (1994). Dicionário filosófico. Trad. Pietro Nasseti. São Paulo : Martin Claret. [1764]

\section{Fontes}

KRAMMER, Dora. Em nome da lei do pior esforço. O Estado de São Paulo. São Paulo, 26 jan. 2005.

KUJAWSKI, Gilberto de Mello. O linguajar de Lula. O Estado de São Paulo. São Paulo, 17 fev. 2005.

VEJA. São Paulo: Abril, 23 fev, 2005, ano 38, nº 8, ed. 1893.

\section{ANEXO}

\section{Em nome da lei do pior esforço Dora Krammer}

$1^{0}$ § Há de haver uma explicação para o empenho do governo em geral e do presidente Luiz Inácio da Silva em particular na consolidação do pensamento banal, da palavra tosca e do ato irrelevante como valores representativos do caráter nacional.

$2^{\mathbf{0}} \S$ Seria de se esperar que, uma vez eleito, Lula fizesse um esforço - aproveitando as condições objetivas oferecidas pelo cargo - para superar suas deficiências de formação e tornar-se de fato um exemplo de ascensão social, política, educacional, cultural, e sobretudo pessoal.

$3^{\mathbf{0}} \S$ Compreendendo um pouco mais a complexidade do universo ao redor, o presidente poderia, assim, traduzi-la com simplicidade e apuro aos milhões que viram nele a realização do sonho do brasileiro que "chegou lá".

$4^{\circ} \S$ Contrariando o curso da lógica, porém, o governo Lula tem andado para trás nesse quesito e parece particularmente interessado em valorizar a insuficiência, incentivar o despreparo, mostrar como é possível "chegar lá" mantendo-se preso exatamente ao que debilita o ser humano e impossibilita o desenvolvimento da coletividade: $o$ desconhecimento.

$5^{\circ} \S$ Os exemplos dessa opção pelo nivelamento por baixo são diversos, constantes e ultimamente oferecidos de forma mais acentuada. A ponto de chamar atenção e despertar desconfiança sobre a possibilidade de essa involução ser proposital.

$6^{\circ} \S$ Não pode haver uma explicação a não ser o propósito previamente definido, para, por exemplo, o presidente da República dirigir-se a uma platéia de funcionários dos 
Correios nos termos em que o fez ontem durante uma solenidade de lançamento de um novo serviço da empresa.

$7^{\mathbf{0}} \S$ A conjugação de argumentos irrelevantes - "duvido que haja no mundo um país que tenha um correio como o nosso" -, raciocínios triviais - "Deus não elege um pernambucano de Caetés todo ano" -, com um português ofensivo à nacionalidade - "a gente tem que ser gentis" - e conceitos socialmente excludentes - "para os de cima o pobre tem que ser pobre a vida inteira" - não combina com os atributos até congênitos de alguém que foi capaz de chegar à Presidência da República.

$8^{\mathbf{0}}$ § Até porque basta observar como ao longo desses dois anos Luiz Inácio da Silva mostrouse perfeitamente apto a adaptar-se aos ditames de determinadas situações, quando quis e a ocasião assim exigiu. Não obstante a preservação da tendência de simplificar a realidade, as extravagâncias - incluindo as idiomáticas - do início sofreram um processo de contenção.

$9^{\circ}$ § Qual o motivo agora dessa regressão ao ponto de origem?

$\mathbf{1 0}^{\mathbf{0}}$ § Apresenta-se como crível apenas a suposição de que o presidente esteja fazendo um tipo, exagerando nas tintas do personagem para alcançar algum objetivo.

$11^{\circ}$ § Como o alvo adiante, admite-se publicamente e sem pejo no governo, até porque assim permite a lei, é a reeleição, lícito concluir que resida aí a razão da opção pelo populismo desabrido que estamos a observar.

$12^{\circ} \S$ Considerando que o presidente sabe falar normalmente (sem preciosismos, mas no limite do linguajar aceitável) quando quer, qual a necessidade de discursar aos carteiros agredindo o português da forma como fez ontem, sem deixar quase nenhuma frase incólume?

$1^{\mathbf{0}} \S$ Não faz jus à campanha do governo de incentivo à auto-estima do brasileiro a suposição de que para agradar aos humildes seja necessário dirigir-se a eles num "companheirês" que desqualifica o idioma, um dos mais fortes símbolos da soberania nacional.

$14^{\circ} \S$ Se os não-instruídos falam errado o português, certamente a maioria não o faz por escolha, charme ou diversão, mas por obra das deformações sociais por todos amplamente conhecida e pelo presidente sistematicamente lembrada.

$15^{\circ} \S$ Trata-se, portanto, não de uma situação a ser enaltecida mas de algo a ser combatido, inclusive e principalmente com o esforço dos "de cima" (cujo representante mais acima é justamente o presidente da República) para elevar o patamar de expectativa de instrução.

$1^{\mathbf{0}}$ § Será cruel para com o Brasil se o departamento de propaganda e marketing do Palácio do Planalto estiver, como parece, empenhado em sustentar a campanha pela reeleição no enaltecimento da figura do presidente da República como o "brasileiro igualzinho a você", ressuscitando um já tentado, e malsucedido, lema de jornada eleitoral anterior.

$17^{\mathbf{0}} \S \mathrm{Em} 2002$, Lula abandonou o nivelamento por baixo, vestiu um figurino mais próximo da representação da média da sociedade e ganhou a eleição. De certa forma e no crucial - a economia - ficou dentro do parâmetro e surpreendeu favoravelmente.

$18^{\circ} \S$ A escolha rendeu perdas na base social de origem, mas manteve o País à tona. Agora, há evidências de que o governo, à falta de discurso para o público que o elegeu dois anos e meio atrás, pretenda assegurar um novo período falando para aqueles que, segundo as pesquisas de opinião, sustentam em alta a popularidade de Lula.

$19^{\circ} \S$ É um caminho. Legítimo e admissível, desde que não signifique a imposição do império da lei do pior esforço a um país tão carente de qualificação.

(O Estado de São Paulo, 26/01/2005) 
Abstract: This work is within the area of research done by LEI Laboratório de Estudos da Intolerância (Laboratory of Studies on Intolerance). It is specifically within the field of linguistic research, and has, as its main objective, "the examination of intolerance and linguistic prejudices in Brazil and the forms of resistance that they trigger, as much in the same language as in other languages". It is intended to establish a difference between prejudice and linguistic intolerance based on the texts of Voltaire (1764) and Bobbio (1990). It will analyze an example of linguistic intolerance found in the written press, an article written by Dora Krammer, published in the newspaper " $O$ Estado de São Paulo" on January 26 $6^{\text {th }}$, 2005. Titled "Em nome da lei do pior esforço" (In the name of the Law of Worst Effort), Krammer expresses her opinion, echoed nationally. The work will examine why discourses such as this can be interpreted as being intolerant.

Key words: Linguistic intolerance; linguistic prejudice; discourse; Portuguese language. 